\title{
Correlation of serum thyroid hormones and prolactin levels to female infertility
}

\author{
Kaliki Hymavathi*, Surekha Tadisetti, Divya Pusarla, Prasuna Pambadi
}

Department of Obstetrics and Gynaecology, Narayana Medical College and Hospital, Nellore, Andhra Pradesh, India

Received: 15 September 2016

Received: 22 September 2016

Accepted: 08 October 2016

\author{
*Correspondence: \\ Dr. Kaliki Hymavathi, \\ E-mail: dr.hymakrreddy@gmail.com
}

Copyright: () the author(s), publisher and licensee Medip Academy. This is an open-access article distributed under the terms of the Creative Commons Attribution Non-Commercial License, which permits unrestricted non-commercial use, distribution, and reproduction in any medium, provided the original work is properly cited.

\begin{abstract}
Background: Infertility is defined as inability to conceive after one year of regular intercourse without contraception. Thyroid dysfunction is known to interfere with several aspects of reproduction and pregnancy. Hyperprolactinemia also adversely affects the fertility potential by affecting pulsatile secretion of Gonadotropin releasing hormone $(\mathrm{GnRH})$ and hence interfering with ovulation. Measurement of these hormones is considered an important component of female infertility work up.

Methods: 100 infertile women are recruited into the study (Study group). 100 healthy fertile women were taken as controls (control group). Thyroid and Prolactin levels estimated in both groups.

Results: Among the study group, $81 \%$ were with primary infertility and $19 \%$ were with secondary infertility. The mean age of the study group was $25.95 \pm 3.79$. $26 \%$ of infertile women with primary infertility were in overweight and obese groups. $3 \%$ with secondary infertility were overweight. $34 \%$ of women with primary infertility were with Thyroid problems.18\% of the hypothyroids were in the overweight and obese groups. Prevalence of hyperprolactinemia was $34 \%$ in study group with mean Prolactin levels of $21.84 \pm 15.65$. $15 \%$ of women with hyperprolactinemia were overweight. $62.5 \%$ of hyperprolactinemics with associated hypothyroidism the rest with hyperthyroidism. These values when compared with controls showed significant $\mathrm{p}$ value 0.012 .

Conclusions: Identifying and treating hypothyroidism and hyperprolactinemia at an early stage can have potentially great preventive value in the screening of all infertile females hence should be included in the primary workup of the infertility female.
\end{abstract}

Keywords: Infertility, Prolactin, Thyroid

\section{INTRODUCTION}

Infertility is defined as inability to conceive after one year of regular intercourse without contraception. ${ }^{1} 75 \%$ of perfectly normal couples will conceive within a period of 6 months, $85 \%$ within one year and $93 \%$ within 2 years. $^{2-4}$ Infertility may be primary (no previous conceptions) or secondary (with history of previous conception but having difficulty currently to conceive). Infertility affects approximately 15 to $20 \%$ of couples globally. Among the female factors contributing to infertility, aberrant function of Hypothalamic- PituitaryOvarian (HPO) axis is relatively common. Apart from causes like, male infertility [30\%], female infertility [35\%] combination of both [20\%] and finally unexplained or idiopathic infertility [15\%]. ${ }^{5}$ Measurement of serum Prolactin and Thyroid hormones especially TSH has been considered an important component of infertility work up in women. Thyroid dysfunction is known to interfere with several aspects of reproduction and pregnancy. Hypothyroidism or hyperthyroidism and even subclinical Thyroid 
dysfunction have been found to be associated with anovulatory cycles, decreased fecundity, and increased morbidity during pregnancy. Hyperprolactinemia also adversely affects the fertility potential by disturbing pulsatile secretion of $\mathrm{GnRH}$ and hence interfering with ovulation. It may result in menstrual and ovulatory dysfunctions like anovulation, amenorrhea and galactorrhea. ${ }^{6}$ Pituitary hormones such as TSH, Prolactin or Growth hormone may act synergistically with Follicle stimulating hormone [FSH] and Lutenizing hormone $[\mathrm{LH}]$ to enhance the entry of extra follicles into growth phase. Studies have shown that even in the absence of hyperprolactinemia, thyroid dysfunction itself may contribute to infertility since Thyroid hormones may be necessary for maximum production of both Estradiol and Progesterone. There has been paucity of data regarding the association between Thyroid disorders and serum Prolactin levels in infertility. So, the aim of this study was to evaluate the status of Thyroid hormones as well as Prolactin levels in infertile females and to correlate their impact on them.

\section{Aims and objectives of the study}

- To assess the status of Thyroid hormones and Serum Prolactin levels in infertile women attending the outpatient department of OBGY of NMCH, Nellore, AP during the period of October 2013-October 2015.

- To prove Thyroid and Prolactin irregularities as contributory factors of female infertility.

\section{METHODS}

\section{Data sources}

A prospective case control study was done in the department of OBGY, NMCH, Nellore, Andhra Pradesh, India for a period of 2 yrs during October 2013 - October 2015.

100 infertile women, attending to the Gynaecology department are recruited into the study (Study group). A similar number (100) of age matched healthy fertile women were taken as controls (Control group).

\section{Inclusion criteria}

1. Diagnosed cases of infertility (both primary and secondary).

2. Age of patients between $20-40$ yrs.

\section{Exclusion criteria}

1. Male factor infertility.

2. Infertile female with $\mathrm{H} / \mathrm{O}$ Tuberculosis or any organic lesion (fibroids etc.).

3. Those with pre-existing thyroid problems and hyperprolactinemia on treatment.
Institutional ethical committee of $\mathrm{NMCH}$, Nellore, AP has approved the study.

All the Infertile women in reproductive age group varying from 20 to 40 years were recruited into the study following detailed history (demography, complaints, martial life, past obstetric medical/surgical) and clinical examination (complete general, systemic and pelvic examination). Apart from routine investigations, specific investigations like Thyroid hormone levels and serum Prolactin were done.

\section{Specific investigations}

\section{Hormonal study}

Serum freeT3, freeT4, TSH and serum Prolactin levels were estimated between the 1-5 days of post menstrual period.

Both are estimated by Chemilumeniscence Immunoassay (CLIA).

\section{Expected ranges of values (Prolactin)}

Normal women $1.2-19.5 \mathrm{ng} / \mathrm{ml}$

Table 1: Expected ranges of values (Thyroid hormone).

\begin{tabular}{|c|c|c|c|}
\hline Hormones & Euthyroid & Hypothyroid & Hyperthyroid \\
\hline FT3 & $\begin{array}{l}2.50-3.90 \\
\mathrm{pg} / \mathrm{ml}\end{array}$ & $<2.50 \mathrm{pg} / \mathrm{ml}$ & $>3.90 \mathrm{pg} / \mathrm{ml}$ \\
\hline FT4 & $\begin{array}{l}0.61-1.12 \\
\mathrm{ng} / \mathrm{dl}\end{array}$ & $<0.61 \mathrm{ng} / \mathrm{dl}$ & $>1.12 \mathrm{ng} / \mathrm{dl}$ \\
\hline $\mathrm{TSH}$ & $\begin{array}{l}0.34- \\
5.60 \mathrm{Miu} / 1\end{array}$ & $\begin{array}{l}>5.60 \mathrm{~m} \\
\mathrm{IU} / \mathrm{L}\end{array}$ & $<0.34 \mathrm{~m} \mathrm{IU} / \mathrm{L}$ \\
\hline
\end{tabular}

\section{RESULTS}

The Present study is a hospital based case control study conducted in the department of OBGY of NMCH. 100 Infertile women fulfilling the inclusion criteria were recruited into the study (study group). Another 100 age matched fertile women were taken as controls (control group) and the levels of Thyroid hormones and serum Prolactin in both groups were studied. Among the study group, $81 \%$ were with primary infertility and $19 \%$ were with secondary infertility (Table 2).

Table 2: Infertility types - study group $(n=100)$.

\begin{tabular}{|ll|l|}
\hline Type of infertility & No of cases & Percentage \\
\hline Primary & 81 & $81 \%$ \\
\hline Secondary & 19 & $19 \%$ \\
\hline
\end{tabular}


Table 3: Age distribution - study v/s control group.

\begin{tabular}{|lllll|}
\hline Infertility & $\begin{array}{l}20-24 \\
\text { yrs }\end{array}$ & $\begin{array}{l}25-29 \\
\text { yrs }\end{array}$ & $\begin{array}{l}30-34 \\
\text { yrs }\end{array}$ & $\begin{array}{l}>35 \\
\text { yrs }\end{array}$ \\
\hline Primary & $31 \%$ & $40 \%$ & $8 \%$ & $2 \%$ \\
\hline Secondary & $4 \%$ & $12 \%$ & $2 \%$ & $1 \%$ \\
\hline Total & $35 \%$ & $52 \%$ & $10 \%$ & $3 \%$ \\
\hline
\end{tabular}

Majority of Infertile women (52\%) in the study group were in the age group of 25-29 years. And only 3\% were of $>35$ years (Table 3 ). The mean age of the study group was $25.95 \pm 3.79$.

With regard to body mass index (BMI) $26 \%$ of infertile women with primary infertility were overweight and obese groups (13\% each). $3 \%$ of infertile women with secondary infertility were of overweight. Overall $29 \%$ of women being overweight and obese.

In the study group, $18 \%$ of the hypothyroids were in the overweight and obese groups, where as in the hyperthyroids, only $1 \%$ was obese and $1 \%$ being underweight. Coming to the control group only $1 \%$ of the hypothyroids were obese and the comparison of both groups in this aspect has shown significant $\mathrm{P}$ value. 34\% of women with primary infertility were hypothyroids $(27 \%)$ and hyperthyroids $(7 \%)$. In those with secondary infertility the corresponding figures were $2 \%$ and $5 \%$ respectively (Table 4).

Table 4: Thyroid and hyperprolactinemia status -study group $(\mathbf{n}=100)$.

\begin{tabular}{|lllll|}
\hline Infertility & Hypothyroid & Hyperthyroid & Euthyroid & Hyperprolactinemia \\
\hline Primary & $27 \%$ & $7 \%$ & $47 \%$ & $79.4 \%$ \\
\hline Secondary & $5 \%$ & $2 \%$ & $12 \%$ & $20.6 \%$ \\
\hline
\end{tabular}

Nearly $41 \%$ of infertile women were found to be with Thyroid problems. This obviously reveals that Thyroid dysfunctions may be the causative factor for infertility to a reasonable extent.

Among the study group prevalence of hyperprolactinemia was found to be $37 \%$ out of which $80 \%$ were with primary infertility, whereas only $19 \%$ of control population were with hyperprolactinemia (Table 4).

Mean Prolactin levels in the Study group 21.84 \pm 15.65 compared with mean levels of Control group 16.62 \pm 9.73 with significant $\mathrm{p}$ value (Table 5).

There are no available studies in the literature regarding relation of BMI to hyperprolactinemia. $8 \%$ of women with hyperprolactinemia were overweight and $7 \%$ were obese. Surprisingly $14 \%$ euprolactinemics among the study group were found to be obese, whereas in the control group $2 \%$ of hyperprolactinemics were overweight. No significant variation $(\mathrm{p}$ value $=0.093$ ) was observed in relation to BMI in study group v/s controls.

Among study group, Hyperprolactinemia alone was seen in $10(16.9 \%)$ but with associated Hypothyroidism in $62.5 \%$. and hyperthyroidism in $44.4 \%$. These values when compared with controls showed significant $\mathrm{p}$ value 0.012 (Table 6).

Table 5: Mean serum prolactin levels - study vs controls.

\begin{tabular}{|llll|}
\hline Groups & Number & Mean \pm sd & p value \\
\cline { 1 - 2 } Study & 100 & $21.84 \pm 15.65$ & 0.005 \\
\cline { 1 - 2 } Controls & 100 & $16.62 \pm 9.73$ & \\
\hline
\end{tabular}

Table 6: Hyperprolactinemia with or without associated Thyroid problem - study v/s control group.

\begin{tabular}{|llllll|}
\hline \multirow{2}{*}{ Thyyroid } & Group & \multicolumn{2}{c|}{ Hyper-prolactinemia } & \multicolumn{2}{c|}{ Euprolactinemia } \\
\cline { 2 - 6 } Hypo-thyroid & $\mathbf{N}$ & $\mathbf{\%}$ & $\mathbf{N}$ & $\mathbf{\%}$ \\
\hline \multirow{2}{*}{ Hyper-thyroid } & Study & 20 & 62.5 & 12 & 37.5 \\
\cline { 2 - 6 } & Control & 7 & 63.6 & 4 & 36.4 \\
\hline \multirow{2}{*}{ Eu-thyroid } & Study & 4 & 44.4 & 5 & 55.6 \\
\cline { 2 - 6 } & Control & 1 & 100 & 0 & - \\
\hline
\end{tabular}




\section{DISCUSSION}

Infertility is a worldwide problem affecting people of all communities, though the cause and magnitude may vary with geographical location and socioeconomic status. It is estimated that globally 60-80 million couples suffer from infertility every year; of which between 15-20 millions are in India alone. ${ }^{7}$ Infertility is known to cause an impact on mental health of the couple and sexual dysfunction. ${ }^{8}$

Thyroid hormones have profound effects on reproduction and pregnancy. Thyroid dysfunction is implicated in a broad spectrum of reproductive disorders, ranging from abnormal sexual development to menstrual irregularities and infertility. Hypothyroidism is associated at times with hyperprolactinemia which adversely affects fertility potential by impairing GnRH pulsatility and thereby ovarian function. Therefore, every infertile female should be investigated for Thyroid and Prolactin irregularities. Present study is attempted to find a correlation between Thyroid status and that of Prolactin in infertile women (both primary and secondary) comparing with the age matched fertile women.

As per (Table 7) the reported figures of primary and secondary infertility are 60 and $40 \%$ respectively. In the present study the corresponding figures are 81 and $19 \%$.

Table 7: Infertility types.

\begin{tabular}{|lll|}
\hline Type of infertility & Primary & Secondary \\
\hline Jungare et al $^{8}$ & $58 \%$ & $42 \%$ \\
\hline Kumkum et al & $60 \%$ & $40 \%$ \\
\hline Present study & $81 \%$ & $19 \%$ \\
\hline
\end{tabular}

\section{Age distribution}

Fertility declines with age. Female fertility is at its peak between the ages 18 and 24 years, while, it begins to decline after age 25 and somewhat at greater rate after age 35 .

Now a day's most of the women are giving importance to education, job and career leading to late marriages and further leading to infertility. Education and career have been associated with deprivation and disappointment in this regard. ${ }^{11}$

In the study of Fupare et al, the mean age was low in infertile women. In our study group $87 \%$ of infertile females were in the age group of 20 to 29 years. Though they are not very elderly may be the above mentioned reasons must have contributed to their infertility. ${ }^{12}$

\section{Infertility and body mass index [BMI]}

Body fat plays a critical role in human reproduction. Obese women experience first a change in their menstrual cycles followed by signs of hirsutism which can be attributed to hormonal imbalance leading to anovulation resulting in infertility. Obesity is commonly seen among the infertiles. In the present study only $29 \%$ of study population were overweight $(16 \%)$ and obese $(13 \%)$ and $70 \%$ are within normal weight range in whom other factors may be contributing to the infertility.

As per Bolumar et al, approximately $12 \%$ of all women were overweight (BMI $>25 \mathrm{~kg} / \mathrm{m} 2$ ) and just over $3 \%$ were obese (BMI $>30 \mathrm{~kg} / \mathrm{m} 2)$. ${ }^{3}$ In the present study group in hypothyroid cases were more in overweight $(10 \%)$ and obese $(8 \%)$ categories. These findings can be explained by the fact that obesity is often associated with chronic low inflammatory state and raised TSH levels observed in obese patients could be due to increased levels of circulating antibodies to Thyroid.

\section{Infertility - thyroid disturbances}

Thyroid dysfunction interferes with human reproductive physiology ending up in infertility. Women with hypothyroidism may not only be infertile but may also have a higher risk of birth defects in their off springs.

As per Table 8 the reported percentages of hypothyroidism and hyperthyroidism in infertile females are in the range of $20-30 \%$ and $18-34 \%$ respectively. But our corresponding figures are $32 \%$ and $9 \%$.

Table 8: Infertility - thyroid disorders.

\begin{tabular}{|lccc|}
\hline Study & Hypothyroid & Hyperthyroid & Euthyroid \\
\hline $\begin{array}{l}\text { Nemade } \\
\text { et al }\end{array}$ & $18 \%$ & $30 \%$ & $52 \%$ \\
\hline $\begin{array}{l}\text { Hivre MD } \\
\text { et al }\end{array}$ & $20 \%$ & $34 \%$ & $46 \%$ \\
\hline $\begin{array}{l}\text { Nupur et } \\
\text { al }^{15}\end{array}$ & $30 \%$ & $17.5 \%$ & $52.5 \%$ \\
\hline $\begin{array}{l}\text { Present } \\
\text { study }\end{array}$ & $32 \%$ & $9 \%$ & $59 \%$ \\
\hline
\end{tabular}

Hypothyroidism was seen in about $20-30 \%$ of infertile females in the above studies of Nemade et al, Hivre et al, Nupur et al. ${ }^{14-16}$ Our corresponding figure is $32 \%$. Hyperthyroidism is seen in above studies ranging from $18-34 \%$, where as in present study it is only seen in $9 \%$ of cases (Table 8).

On the whole prevalence of hypothyroidism is found to be more in coastal areas like ours. When it comes to Thyroid disorders in age matched fertile controls there were only $11 \%$ and $1 \%$ of hypo and hyperthyroids respectively. But in them Thyroid disorders have set in only after having children. There was no history of infertility in the control group that can be attributed to the present Thyroid problems. 


\section{Thyroid parameters - study vs controls}

Mean FT4 and TSH levels in the present study were with a significant $p$ value $(0.0001)$ in comparison with studies of Nissreen FA, Elzobir et al, Nemade ST et al, Shamsuddin M et al. ${ }^{14,17,18}$ Mean FT3 levels of study v/s controls groups was found to be significant in various studies where as in the present study the $\mathrm{p}$ value is found to be 0.57 with no reasonable explanation.

\section{Serum Prolactin}

One of the major causes of hyperprolactinemia is a Prolactinoma or lactotrophic adenoma (functioning pituitary adenomas), which produces excessive Prolactin. But at times in association with Thyroid disorders, hyperprolactinemia can cause menstrual irregularities, hypogonadism and infertility. The prevalence of hyperprolactinemia in infertile group is more when compared to controls in the present study.

Table 9: Serum Prolactin levels - study group.

\begin{tabular}{|c|c|c|}
\hline Hyperprolactinemia & $\begin{array}{l}\text { Primary } \\
\text { infertility }\end{array}$ & $\begin{array}{l}\text { Secondary } \\
\text { infertility }\end{array}$ \\
\hline Jungare et $\mathrm{al}^{9}$ & $42 \%$ & $58 \%$ \\
\hline Priyanka et al ${ }^{19}$ & $59 \%$ & $41 \%$ \\
\hline Present study & $79.4 \%$ & $20.6 \%$ \\
\hline
\end{tabular}

As per the above studies the percentages of hyperprolactinemics in both types of infertility (primary and secondary) were not markedly different. Whereas in the present study $79.4 \%$ of hyperprolactinemics were in the primary infertility group and only $20.6 \%$ were in secondary infertility group (Table 9).

In all the above studies the mean Prolactin levels (study vs. controls) were with a significant $p$ value. In the present study also mean Prolactin levels were found to be with significant $\mathrm{p}$ value (0.005) (Table 10).

Table 10: Mean serum prolactin levels - study v/s controls.

\begin{tabular}{|llll|}
\hline Study & Cases & Controls & P value \\
\hline Elzobir at el $^{16}$ & $40.73 \pm 37.07$ & $8.13 \pm 3.66$ & $<0.001$ \\
\hline Hivre at el & $11.65 \pm 4.67$ & $50.24 \pm 42.11$ & $<0.05$ \\
\hline $\begin{array}{l}\text { Priyanka at } \\
\text { el }^{19}\end{array}$ & $21.52 \pm 17.71$ & $15.22 \pm 9.54$ & $<0.05$ \\
\hline Jungare at el & $67.90 \pm 20.05$ & $11.60 \pm 5.19$ & $<0.001$ \\
\hline $\begin{array}{l}\text { Triumalasetty } \\
\text { at el }^{20}\end{array}$ & $52.9 \pm 27.17$ & $12.58 \pm 6.9$ & $<0.001$ \\
\hline Present study & $21.84 \pm 15.65$ & $16.62 \pm 9.73$ & 0.005 \\
\hline
\end{tabular}

Age v/s prolactin levels - study v/s controls

In the study by Tasneem et al, the highest incidence (51\%) of hyperprolactinemia was observed in the age group 22-27 yrs. In our study group, $28 \%$ of hyperprolactinemics are seen in that age group and only $6 \%$ were in the $30-35$ yrs age groups.

\section{BMI v/s Prolactin levels - study v/s controls}

In the study group about $15 \%$ of hyperprolactinemics were in the overweight group compared to only $2 \%$ in the control group. $14 \%$ of euprolactinemics were found to be overweight. In the study by Ernst B et al, a significant positive correlation of Prolactin was observed with increased body weight and BMI indicating that Prolactin may be related to obesity. ${ }^{19}$

Grimaldi $\mathrm{F}$ et al in another study comparing basal and TRH stimulated Prolactin levels in obese and non-obese individuals reported higher basal levels of Prolactin in obese individuals. ${ }^{20}$ However, this is in contrast to a recent study in general population where no correlation was observed between serum Prolactin and obesity. In the present study context also the $\mathrm{P}$ value is found to be insignificant (0.093), thus explaining not much relation between hyperprolactinemia and BMI levels.

\section{Hyperprolactinemia with or without associated thyroid problems}

Pathologic hyperprolactinemia is generally applied for the situation in which Prolactin level increases because of some reason other than physiologic causes is a common problem in reproductive dysfunction affecting about $33 \%$ of infertile women. Some of the women with hyperprolactinemia might have primary hypothyroidism, characterized by low serum levels of FT4 due to decreased negative feedback on the HPO axis resulting in increased secretion of Thyrotropin releasing hormone (TRH) stimulating thyrotrophs and lactotrophs, thereby increasing the levels of both TSH and Prolactin. Increased levels of serum Prolactin have been reported in $30 \%$ of patients with primary hypothyroidism.

\section{Correlation of thyroid and prolactin levels}

The magnitude of serum Prolactin is proportional to the increase in TSH values and basal gonadotropin concentrations are also elevated in this condition. In one study, the serum Prolactin level was found to be elevated in patients with untreated primary hypothyroidism.

The correlation between TSH and Prolactin was studied in 2006. It was observed that incidence of hypothyroidism in hyperprolactinemia was $25.5 \%$. The ratio of proportions between hyperprolactinemia and hypothyroidism was 5:1 stating that in every five hyperprolactinemic patients one had hypothyroidism. So it was concluded that there is a positive correlation between TSH and Prolactin.

In the study by Hivre et al also, there was a high prevalence of hypothyroidism in infertile females associating with hyperprolactinemia. Hyperprolactinemia 
was depicted in $51 \%$ of the infertile women while it was only $10 \%$ in the control group. In present study, the serum Prolactin and Thyroid levels in the infertile group were found to be high as compared to those in control group and has significant $\mathrm{p}$ value (0.012). The incidence of hypothyroidism in the hyperprolactinemic subjects in the infertile women was found to be highly significant than in the fertile women. Therefore estimation of Thyroid and Prolactin levels are mandatory in the work up of all infertile women.

\section{CONCLUSION}

The concept behind our work was to correlate Thyroid hormones and serum Prolactin with female infertility. Our findings support the hypothesis that women with primary infertility have subtle disturbances in Hypothalamic-pituitary-ovarian axis compared to their fertile counterparts. There is a continuous interaction between the Thyroid gland and gonadal axis before and during pregnancy. Hypothyroidism influences ovarian function by increasing the secretion of Prolactin and decreasing levels of sex-hormone-binding globulin. The present study showed high prevalence of hypothyroidism in infertile women when compared with fertile counter parts. We also found that there was an increase in the Serum Prolactin levels in infertile women as compared to the fertile ones in the control group. The incidence of hyperprolactinaemia in the infertile subjects in the present study population was found to be significantly high.

Long standing hypothyroidism may develop ovulatory dysfunction, and hyperprolactinemia. So identifying and treating hypothyroidism at an early stage before the onset of ovulatory dysfunction and hyperprolactinemia, can have potentially great preventive value. So Thyroid screening of all females of early reproductive age group should be done so as to detect subclinical Thyroid problems and to prevent infertility risk at a later stage. Hence estimation of Thyroid hormones and Prolactin levels should be included in the primary workup of the female infertility.

\section{Funding: No funding sources}

Conflict of interest: None declared

Ethical approval: The study was approved by the Institutional Ethics Committee

\section{REFERENCES}

1. Sharma P, Prasad S. Female infertility and its correlation with serum Prolactin and TSH Concentration-An unmatched case control study. Journal of pharmaceutical and biomedical sciences. J Pharm Biomed Sci. 2013;30(30):902-7.

2. Southam AL. What to do the normal infertile couple. Fertile Sterile. 1960;11;543.
3. Guttmacher F. Factors affecting normal expectancy of conception. J American Medical Association. 1956; $161: 856$.

4. Gill HS, Bedi GK. Correlation of TSH and Prolactin Levels in Patients with Primary Infertility Scholars Journal of Applied Medical Sciences Sch. J App Med Sci. 2014;2(4B):1267-19.

5. Hendershot GE, Mosher WD, Pratt WF. Infertility and age: An unresolved issue. Fam Plann Perspect. 1982;14:287.

6. Mishra R, Baveja R, Gupta V. Prolactin levels in infertility with menstrual irregularities. J Obetet Gynecol India 2002; 52:40 -3.

7. Sudha G, Reddy KSN. Causes of female infertility: A crosssectional study, International journal of latest research in science and technology. 2013;2(6):11923, 2278-5299.

8. Shamali J, Seema V. Hyperprolactinemia and Its Comparison with Hypothyroidism in Infertile Women International Journal of Recent Trends in Science And Technology. 2013;8(2):106-8.

9. Avasthi K, Kaur J, Gupta S. Hyperprolactinema and its correlation with hypothyroidism in infertile women. J Obstet Gynecol India. 2016;56(1):68-71.

10. Faria DEP, Grieco SC. The effects of infertility on the spouses' relationship. Revista da Escola de Enfermagem da USP. 2012;46(4):794-801.

11. Fupare S, Jambhulkar RK. Correlation of thyroid hormones with infertility in reproductive age group women: Indian Journal of Basic and Applied Medical Research. 2015;4(4):488-95.

12. Nemade ST, Momin AA, Naik PS. The Association of Thyroid Profile with Primary Infertility in Females. International Journal of Health Sciences and Research. 2015.

13. Tirumalasetty S. Clinical study of thyrotropin and prolactin levels in women with primary infertility, IJPRBS. 2013;2(3):107-13.

14. Hivre MD, Bhale DV. Study of Serum TSH and Prolactin Levels in Patients of Female Infertility; International Journal of Recent Trends in Science and Technology. 2013;9(1):144-5.

15. Nupur H, Andaleeb F, Premlata M. Correlation of Prolactin and Thyroid Hormone Levels in Infertile Women. Sch Acad J Biosci. 2015;3(1A):1-2.

16. Nissreen FA, Hassan EE. Assessment of Serum Levels of Prolactin in Sudanese female patients with Primary Hypothyroidism- Khartoum State. Journal of Biomedical and Pharmaceutical Sciences. 2014;4(32):1-4.

17. Shamsuddin M. Study of thyoid hormone levels and pituitary thyroid axis in chronic renal failure; Unique Journal of Medical and Dental Sciences. 2014;02(04):53-7.

18. Bolumar F, Olsen J. European Body Mass Index and Delayed Conception: A European Multicenter Study Of Infertility and Subfecundity. American journal of Epidemiology. 2000;151:11.

19. Ernst B, Thurnheer M, Schultes B. Basal serum prolactin levels in obesity-unrelated to parameters of 
the metabolic syndrome and unchanged after massive weight loss. Obes Surg. 2009;19(8):1159-62.

20. Grimaldi F, Mazzolini A, Paterniti BR, Torossi I, Proto G, Bertolissi F. Changes in secretion of prolactin in obesity. Minerva Endocrinol. 1990;15(4):267-71.
Cite this article as: Hymavathi $\mathrm{K}$, Tadisetti $\mathrm{S}$, Pusarla D, Pambadi P. Correlation of serum thyroid hormones and prolactin levels to female infertility. Int J Reprod Contracept Obstet Gynecol 2016;5:4018-24. 